\title{
The Interaction between Culture and Space and the Experience of an Architectural Studio
}

\author{
Sevim Ateş Can \\ Faculty of Engineering and Architecture, Department of Architecture, Mehmet Akif Ersoy University, Burdur 15030, Turkey
}

\begin{abstract}
The issues of analyzing the cultural differences in architecture, and the interaction between culture and space have gained importance in many respects both in practice and in education. "Culture" and conservation of the "cultural heritage" have a place in the conditions for the "architectural education" put forward by the UNESCO (The United Nations Educational, Scientific and Cultural Organization)/UIA (International Union of Architects) Council during the 2002 meeting in Berlin. For this purpose, cultural, social, urban, environmental and architectural values and issues of architectural heritage were defined as specific subjects that should be considered in the preparation of the curriculum to build up a sense of responsibility. From this point of view, this paper aims to propose an educational process for dealing with the sense of cultural heritage and its survival in the modern world, and shares the products of the work carried out at the Project 4 Studio at Faculty of Fine Arts, Department of Interior Architecture, Yeditepe University, as the studio training is the main component of architectural education. The main issue of the paper is to present some examples of the student projects and to consider the importance of design studio, which can gain knowledge about cultural and architectural heritage and develop students' skills to adopt and be respectful to traditional values.
\end{abstract}

Key words: Culture, space, cultural and architectural interaction, heritage, architectural education.

\section{Introduction}

Architecture is a form of cultural expression. The effect of "culture" on architecture cannot be denied. Özer [1] states the culture-architecture interaction as follows: "Architecture is perhaps the foremost among the branches of culture that are under the direct influence of civilization. Factors like construction methods, tools and materials enable architecture to show great differences between countries, regions, cities and neighborhoods even at the same period...".

The concept of culture, in the most general sense, reflects the spiritual (social and psychological) and material production of a society within the historical process. Spiritual production comprises traditions, customs and habits, beliefs and behavioral patterns, whereas material production comprises equipment and architecture. In this context, culture also finds

Corresponding author: Sevim Ateş Can, associate professor, research fields: architectural design, education and studio work and historical cities, preservation and sustainable design. E-mail: atessevim@gmail.com. expression in a society's cultural life, in its life style, in the form of sensing and perception, attitudes, values or belief systems [2].

Rapoport stressed three general views about the concept of culture as follows: "One defines it as a way of life typical of a group, the second as a system of symbols, meanings and cognitive schemata transmitted through symbolic codes, the third as a set of adaptive strategies for survival related to ecology and resources" [3].

He explains the importance of socio-cultural factors in the creation of spaces as follows: “...socio-cultural variables are primary, with ecological ones, such as climate, materials and ways of making a livelihood secondary, constraining or modifying..." [3].

Similarly, Vitruvius [4], who is believed to have lived between 90-20 B.C., emphasizes that an architect, in addition to his knowledge of technology, must also be informed about other fields of science and art as well as social issues. He emphasizes this with his following words: "The architect must be 
equipped with different fields of science and various disciplines...”. Moreover, he states that architecture depends on order, harmony, symmetry, conformity and economy. He associates the concept of "conformity" with "tradition" and gives the following explanation: “...when a work of art is created with competence according to valid principles, the perfect form emerges. It is inspired by traditions, usage and nature...”. He also explains the importance of traditions based on the order and perception used for the temples built in the previous periods.

Architecture is a science that requires multidirectional thinking. Thus, in addition to the technical knowledge required for the design process, it also requires social and cultural awareness.

\section{Design Process in the Studio}

This process comprises four phases in the following sections.

\subsection{Assignment of the Topic}

In the first phase of the studio, the students are assigned topics that they will work on. A food and beverage space-a restaurant, is taken as a "model" for the work item because restaurants have an important place in our daily lives. There are food and beverage spaces of different cultures in different countries and they play an important role for the people of that country to learn about this culture. The food and beverage culture of the community on which the design of space will be based is also included in this research. Thus, the local culture is analyzed all-round.

\subsection{Research Phase}

In this phase, each student researches in full the culture he has chosen worldwide. In this process, the concept of the reflection of national and local culture on architecture is analyzed through architectural spaces of different countries. During this analysis, the student also researches the social structure, religion and art of that culture. Architectural works are presented. Architectural components such as material, color, and fabric are analyzed. In this context, each student chooses one of the different cultures worldwide and tries to learn about it and present it. $\mathrm{He} /$ she researches the history, geography, folklore and art (painting, sculpture, music and gastronomy) of the culture he has chosen. In the later phase, he/she examines the reflection of the culture on architecture.

\subsection{Design Phase}

In the third phase of the studio, the students are asked to render their gains of this research in the restaurant that they design. The students, on the one hand, analyze the function diagram (restaurant and service entrances, main space, cloakroom, service spaces, kitchen and toilet) and the constructive details that constitute technical issues related to the space and, on the other hand, work on the formation of an identity for the space. Just at this point, cultural factors step in and shape the design. In this context, the aim is to make the students see the similarities and differences between different climatic and cultural geographies while making this interpretation through their own projects. It is believed that certain sensitivity about the preservation of the cultural and architectural heritage will be created through these studies.

It has been emphasized at the meeting of the UNESCO (The United Nations Educational, Scientific and Cultural Organization)/UIA (International Union of Architects) Council that it is necessary to be aware of the regional and cultural traditions and applications and there should be differences that reflect this variety in the curriculum [5]. For this purpose, awareness of responsibilities toward human, social, cultural, architectural, and environmental values, as well as architectural heritage, are emphasized in the curriculum. The students are required to gain the ability to act with knowledge of historical and cultural precedents in local and world architecture and create an understanding of heritage issues in the built 
environment [6].

In this context, the studio enables the students to be informed about cultural differences and local architectural issues as a result of their researches and interpretation in their design.

When forming a space, it is possible to use the data in a modernized way together with today's technology and materials or in a totally traditional way. The students determine this. However, it is required that this is reflected on the design, not as an imitation but as a source of inspiration.

İnceoğlu [7] states that local and traditional architecture is used as a source of inspiration in the modern period and today. İnceoğlu [7] also states that, in the works of Aalto, traces of the local-traditional architecture of his country, and in the architecture of Wright, traces of local-traditional are found. And in the third-world countries, the usage of local as a source of inspiration has gained a stylistic characteristic.

Culture is at the same time considered to be one of the important keystones for the sustainable development together with people/community, environment and economy. In this context, the interaction between "culture" and "heritage" becomes important. Education is the most important tool of sustainable development. It plays an important role in the introduction and endearment of cultural heritage to the future generations and in the future generations' gaining preservation awareness. The role of education cannot be denied for the protection and usage of traditional culture and heritage for sustainable development. Therefore, the related departments of the universities have a great responsibility.

To enable the students to learn the reflection of not only the culture of his own country but also the world cultures on architecture and to be informed about these cultures, work was carried out on a wide range at the studio work. Thus, through research carried out and designs based on this research, the student understands the great role culture plays in the formation of architectural identity.

These spaces were designed not on the geography where the culture and architecture emerged but in Istanbul. For this reason, it is important to introduce to the people who visit the space not only the food culture of that community but also the local architecture. In other words, the food culture of a community is brought to life in an ambiance where the architecture of that community is also felt in the space.

\subsection{Presentation}

During this phase, the students present their work that have reached a certain competence to a jury and develop their work through the criticism they receive.

\section{Some Examples from Architectural Design Studio}

\subsection{Greek Restaurant}

The design of this project was inspired by ancient Greek architecture (Fig. 1). The "agora", which is the public space in the Greek architecture, is the starting point of the design. The mezzanine is shaped around the agora. Both the floor covering and the differentiation at the ceiling emphasize the agora horizontally and vertically. The feature of assembly in the public area is symbolized by the bar that is positioned at the center (Fig. 2).

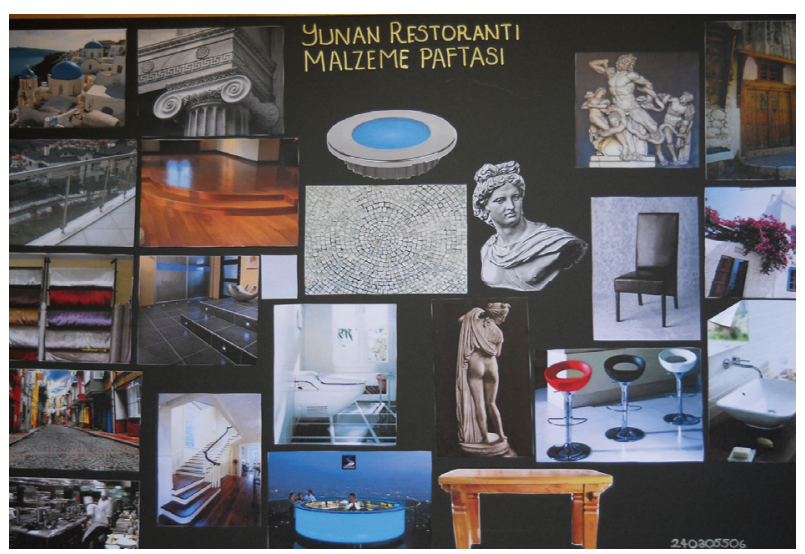

Fig. 1 Research studies about Greek culture.

Source: studio project of A. Öztürk, supervised by S. A. Can [8]. 


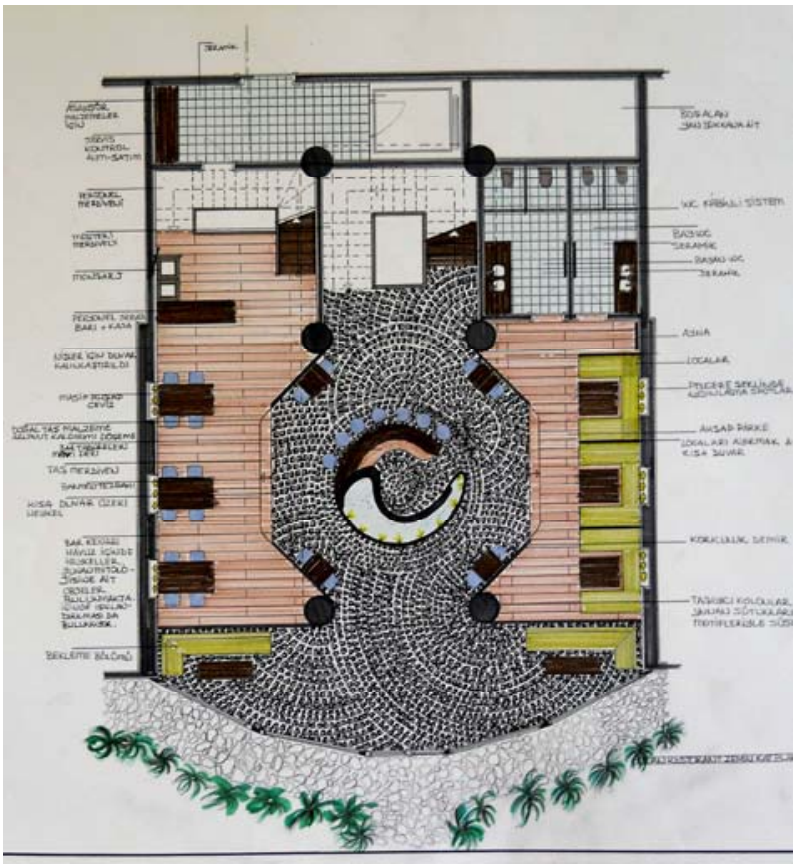

(a)

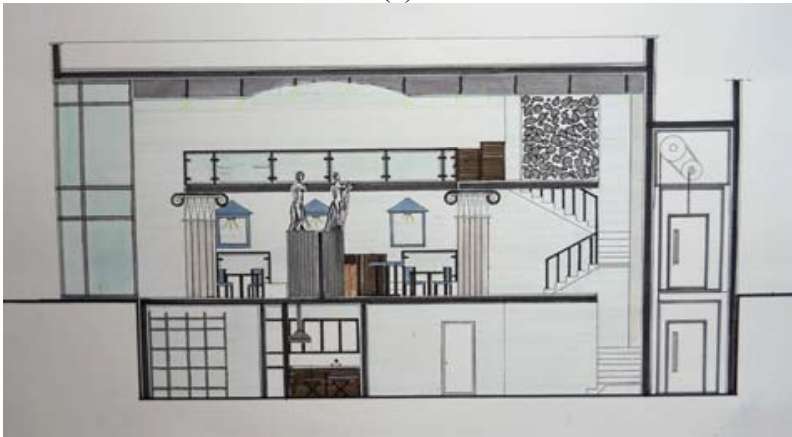

(b)

Figs. 2 Greek restaurant: (a) plan; (b) section.

Source: studio project of A. Öztürk, supervised by S. A. Can $[8]$.

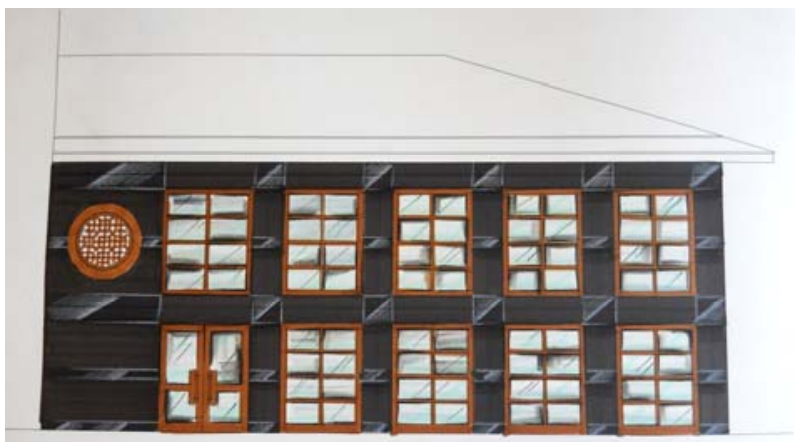

Fig. 3 Chinese restaurant: facade.

Source: studio project of Ö. Sağat, supervised by S. A. Can [8].

One facade of the space that was designed faces the exterior. This facade that forms the entrance with its transparent structure and the external and internal covering invites the people in and canalizes them to the "agora-square". Thus, it creates an effect of an open space for the project. This area that rises two-floors high directs the client to a different ambiance with its sky-like effects. The bar is positioned around a pool and a statue in the center of the agora.

Greek culture was a source of inspiration for the design of this project. "Agora" which creates the public spaces of the Greek architecture creates a starting point of the design.

\subsection{Chinese Restaurant}

Chinese architecture is one of the main architectures of the world. It ultimately reflects the effects of Chinese culture. Thus, the cultural effect has dominated the design of the space. Traces of Chinese culture have been created on the facade that faces the main road on which the restaurant is located. Therefore, use and design of wood, which is the most important material of Chinese architecture, has a dominant effect on the facade. The use of dark colored stone (anthracite) covering for the material and color choice was also inspired by this architecture (Fig. 3).

The design of the space is a synthesis of the traditional and the modern. Therefore, while the restaurant was designed as modern space, elements of far eastern culture and architecture were also included. Wood was mainly used for interior floor covering. The entrance and the bar area have anthracite colored stone floor covering (Fig. 4).

The mezzanine was designed as the eating section of the restaurant (Fig. 4). The covering materials used for the ground floor were also used for the mezzanine to allow continuity between floors. Four areas are reserved as traditional eating spaces. Traditional use of wood in Chinese architecture is interpreted in the partitioning of these spaces. While the traditional sections are under the effect of the dense and dark colored wood, the modern dining section is organized with light colored seating elements and tables and thus 
the contrast between the traditional and the modern is emphasized also with the choice of color and furniture (Fig. 5).

\subsection{Far East Restaurant}

Another example that reflects far eastern culture on the design of an architectural space is the seafood restaurant. The cultural identity is the starting point of the design also for this project. Elements and considerations such as material, color, texture and geometry that shape the architectural design were determinative for this project (Fig. 6).

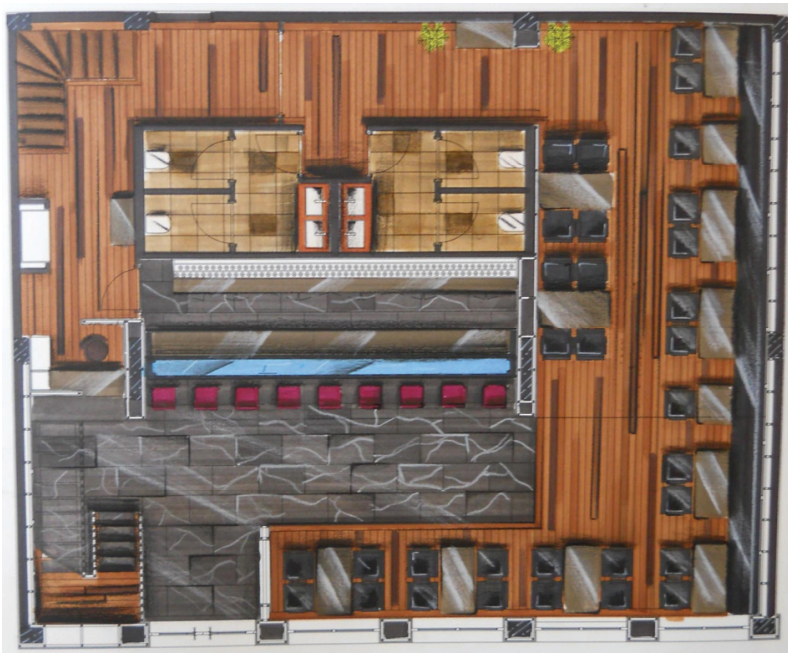

(a)

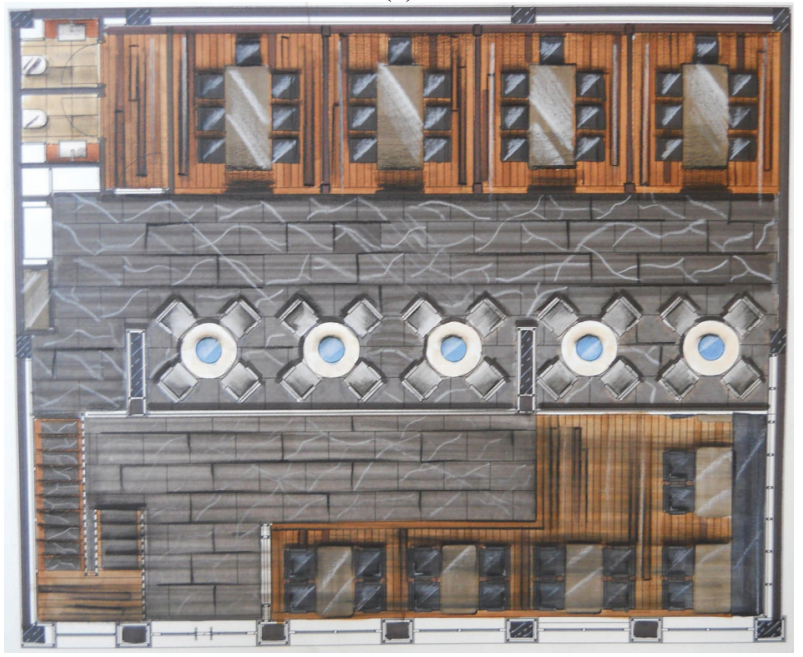

(b)

Fig. 4 Chinese restaurant: (a) ground floor plan; (b) mezzanine.

Source: studio project of Ö. Sağat, supervised by S. A. Can [8].

\subsection{Ottoman Restaurant}

A classical Ottoman restaurant was designed in this project (Fig. 7). The aim was to create a grand and pompous interior space architecture to reflect Ottoman culture. Therefore, Ottoman patterns were used as ornamental elements mainly in the interior space. Ornaments reflecting Ottoman art were used for the partitioning elements, ceiling ornaments, horizontal moldings and floor covering patterns inside the space. Furniture, lighting elements and curtains used in this space are elements that reflect Ottoman culture.

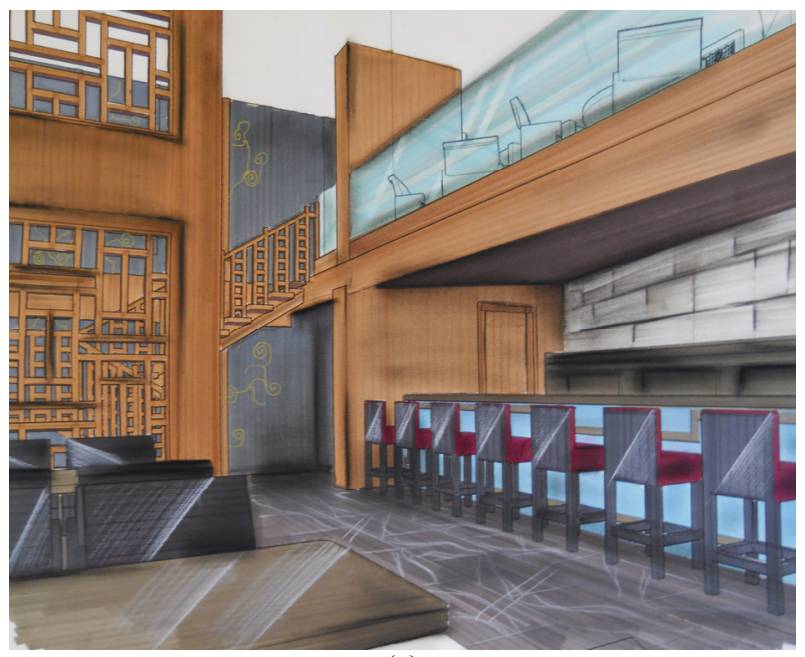

(a)

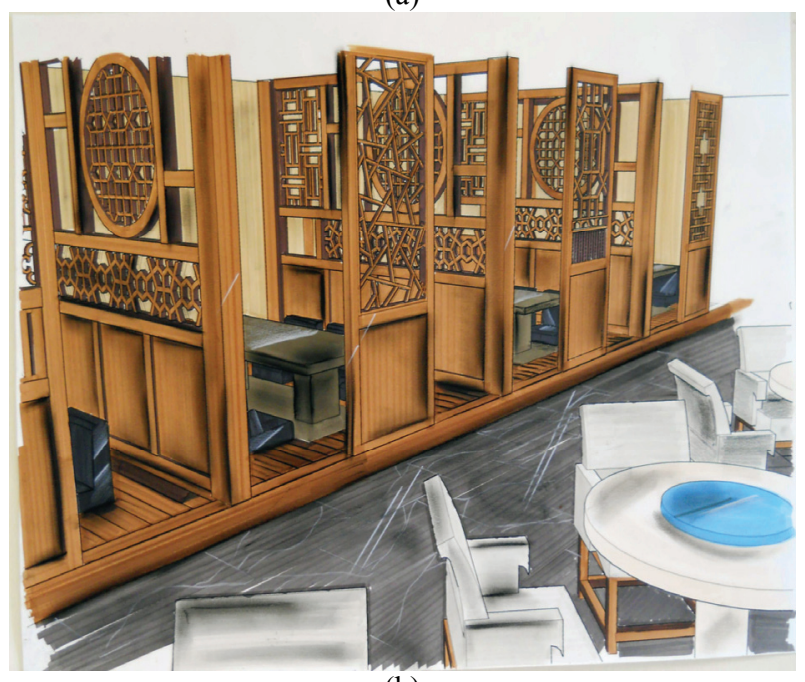

(b)

Fig. 5 Chinese restaurant: (a) general perspective; (b) traditional eating spaces.

Source: studio project of Ö. Sağat, supervised by S. A. Can [8]. 


\subsection{Italian Restaurant}

The design was made for an oblong space. The design has a continuity towards the interior that is created by a seating element that starts on an organic line at the entrance and the bar unit that is articulated to it (Fig. 8a). A pizza oven is situated opposite the bar unit. The main element of the interior design is the traditional Italian pizza oven (Fig. 8b). It is also visually emphasized as an architectural element with its chimney that continues inside as well as on the roof. The oven made with clay elements is enriched with colored ceramic pieces. Two-way curvilinear organic lines lead us to the eating section. Here, different seating groups are designed with different seating layouts. The continuous curvilinear line at the ground floor level is maintained at the ceiling level as well. On the ceilings, wavy wooden bands continue from the

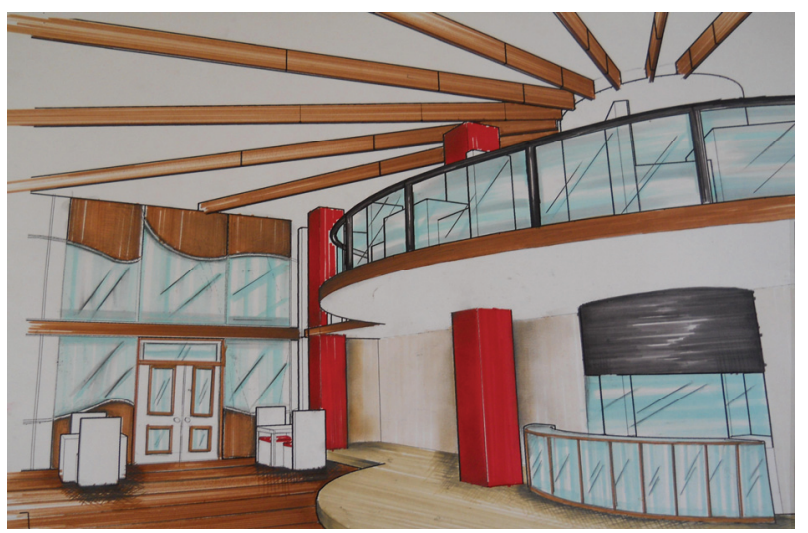

(a)

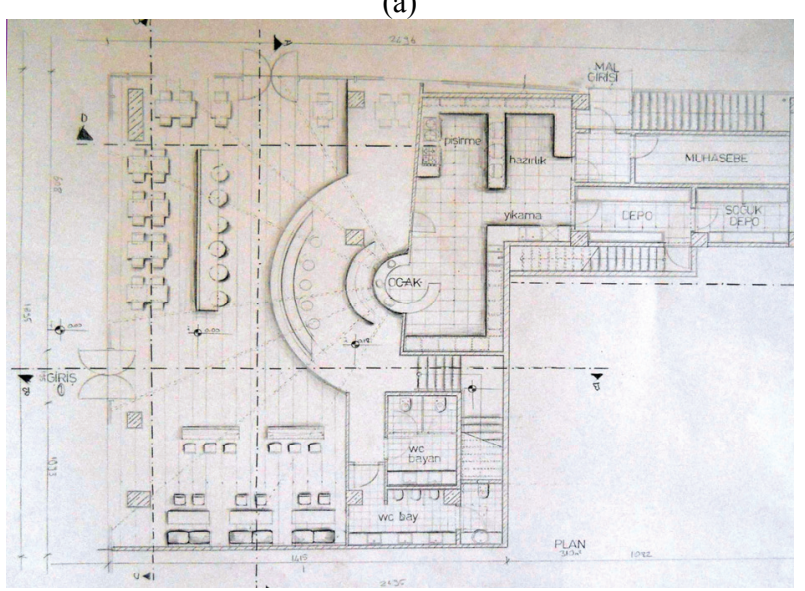

(b)

Fig. 6 Far east restaurant: (a) perspective; (b) plan. Source: studio project of E. Baran, supervised by S. A. Can [8].

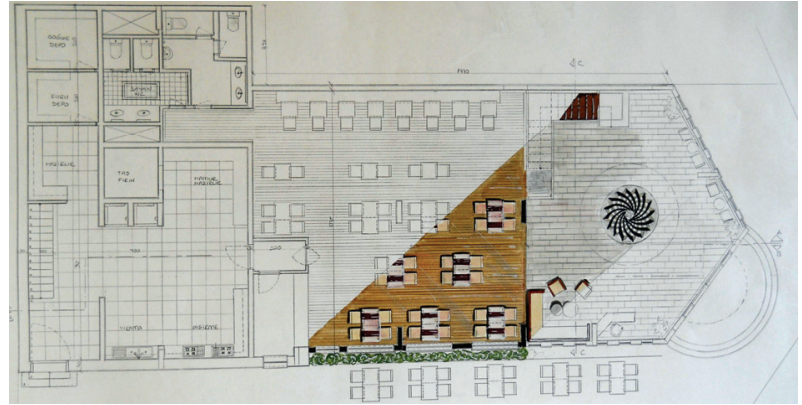

(a)

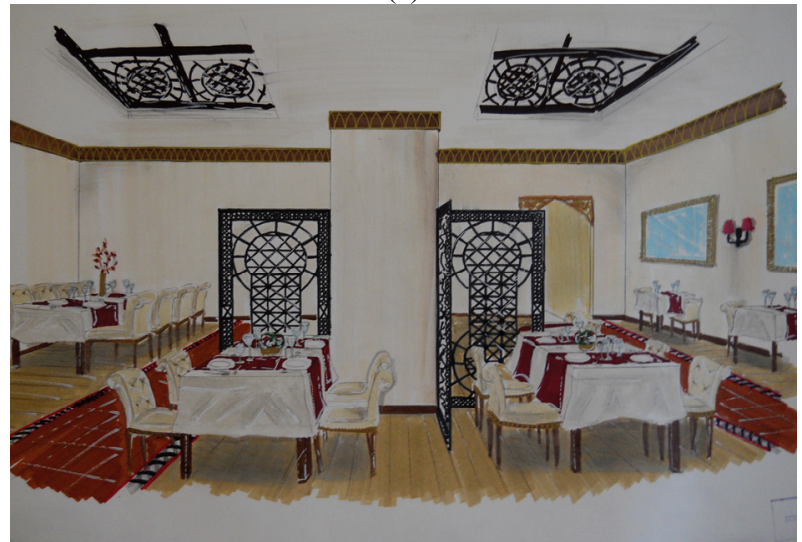

(b)

Fig. 7 Ottoman restaurant: (a) perspective; (b) plan.

Source: studio project of R. Gümüştekin, supervised by S. A. Can [8].

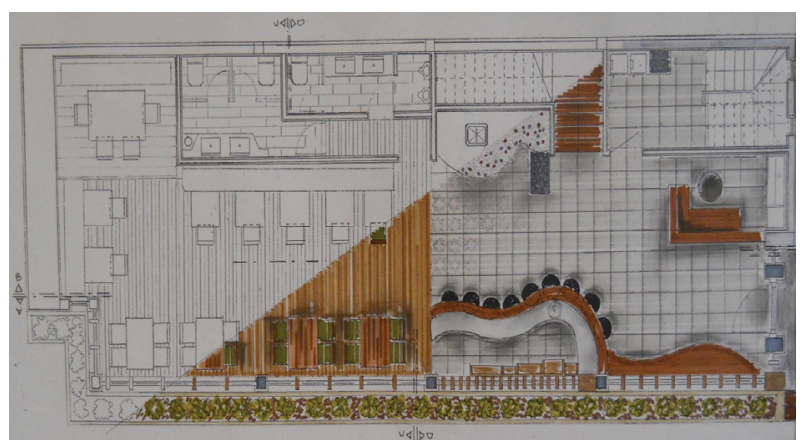

(a)

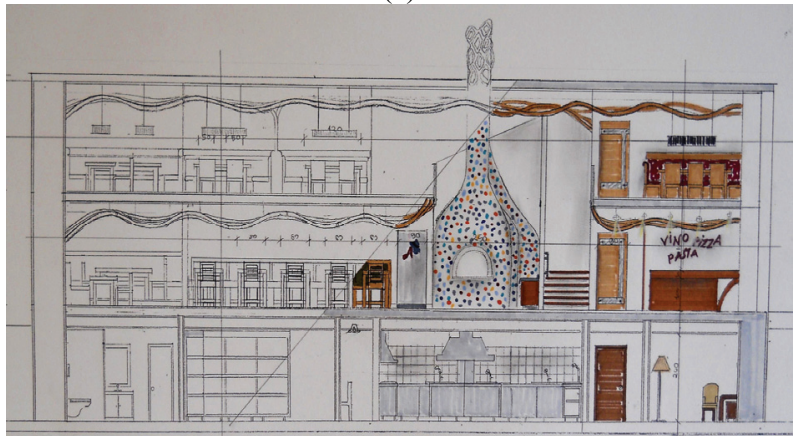

(b)

Fig. 8 Italian restaurant: (a) plan; (b) section.

Source: studio project of D. Ertuğ, supervised by S. A. Can [8]. 


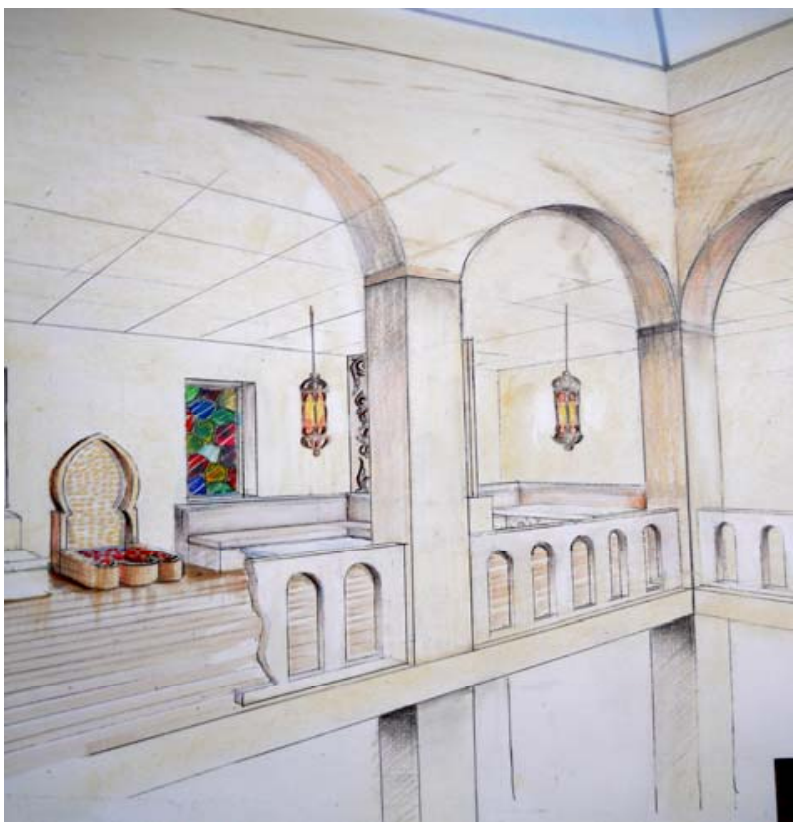

(a)

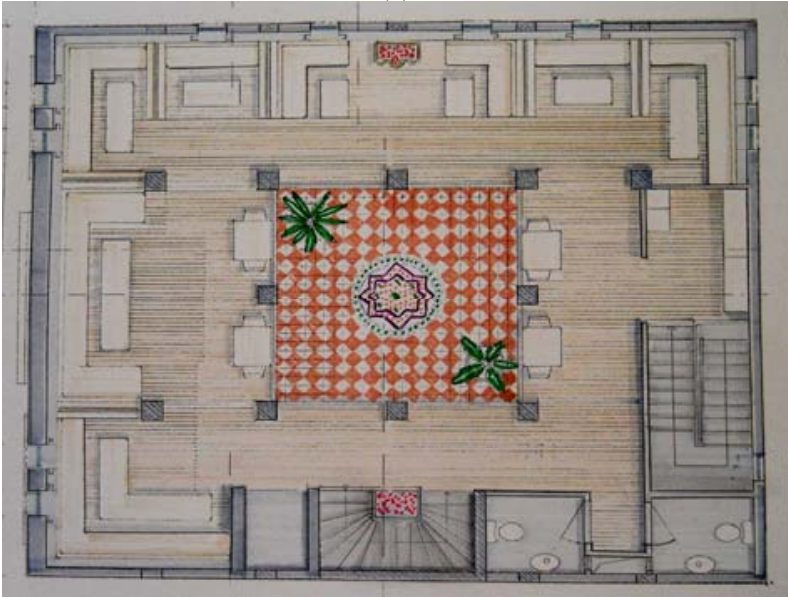

(b)

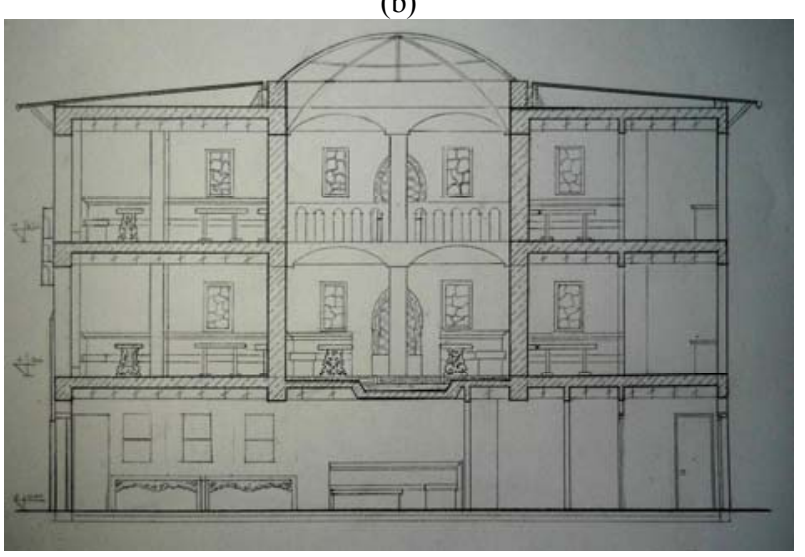

(c)

Fig. 9 Moroccan restaurant: (a) perspective; (b) plan; (c) section.

Source: studio project of N. Baysal, supervised by S. A. Can $[8]$. entrance towards the interior of the space.

Wood inlays are used on the facade to enable continuity between the internal and external space. The bar section is partially concealed with densely organized vertical wooden bands. On the other hand, the wooden bands are less densely organized for the eating section and the visual communication with the external space is more emphasized. Wooden moldings of the bar section continue at the upper floor and the name of the restaurant is planned to be on the beam. However, the entrance section has medium density.

The beam between the mezzanine and the ground floor has dense and wavy wood pieces. The curvilinear organic design idea is reflected on the facade. The upper section mezzanine is designed more transparently. Moreover, a green texture in the form of a thin band is designed along the facade. At the level of the eave, lighting has been provided inside the protruding wooden band that runs along both façades of the building.

\subsection{Moroccan Restaurant}

In this project, Moroccan culture, together with its traditions, art and architecture has been a source of inspiration. The introvert feature of Arabic life was determinative for the design of the space. Therefore, the main element of the space is the "interior courtyard" (Fig. 9). Life inside this space is built around this courtyard. The water element is used widely in the space. Effects of Moroccan culture and art can be seen on the furniture design, lighting elements, partitions between the eating sections and floor covering motives.

\section{Conclusions}

The cultural diversity around the world and the architectural heritage that are the reflection of this diversity during the historical process are the common property of all mankind. The owners of this heritage are not only us but also the future generations. Education is the most important tool for the 
preservation of the heritage that is one of the keystones of sustainable development. In this context, studio education has an important task within the architectural curriculum.

As architectural design is a work of analysis and synthesis, besides the main concepts such as technological efficiency, functionality and aesthetics, the integration of the "cultural context" into design must be ensured for the studio education. It must be remembered that students who gain awareness about the architectural heritage created in different regions, will be sensitized to preserve cultural and architectural heritage.

\section{References}

[1] Özer, B. 2000. Kültür, Sanat, Mimarlı (Culture, Art, Architecture). Istanbul: YEM Publishing. (in Turkish)

[2] UNESCO. 1990. Mimarlar Odasl, Kültürel Gelişmenin Dünya Onyıl ve Türkiye (Chamber of Architects, the
World Decade of Cultural Development and Turkey). Istanbul: E Publishing. (in Turkish)

[3] Amos, R. 1980. 1980. "Cross-Cultural Aspects of Environmental Design." In Human Behavior and Environment, edited by Altman, I., Amos, R., and Joachim, F. W. New York: Plenum Press.

[4] Vitruvius. 1998. Mimarlı Üzerine On Kitap (Ten Books on Architecture). Istanbul: YEM Publishing, 7-10. (in Turkish)

[5] UNESCO/UIA. 2005. UNESCO/UIA Charter for Architectural Education. Revised ed.. Tokyo: UIA General Assembly.

[6] UNESCO. 2003. "Conclusions and Recommendations of the Conference: Linking Universal and Local Values: Managing a Sustainable Future for World Heritage." UNESCO. Accessed October 20, 2014. http://whc.unesco.org/archive/2003/Amsterdam_05_2003 en.pdf.

[7] İnceoğlu, M., and İnceoğlu, N. 2004. Mimarlikta Söylem-Kuram Ve Uygulama (Expression-Theory and Practice in Architecture). Istanbul: Tasarım Publishing Group. (in Turkish)

[8] Can, S. A. 2011. Design Studio IV, 2010/2011. Istanbul: Yeditepe University Turkey. 